\title{
Historias que cuentan los gitanismos en los Catauros de Fernando Ortiz
}

\author{
Ivo Buzek ${ }^{*}$ \\ Universidad Masaryk, República Checa
}

\begin{abstract}
Resumen
El artículo analiza la relación entre diferentes aspectos que pueda abarcar el diccionario monolingüe: ser testigo de la historia del léxico, representar un género del discurso pedagógico o ser un símbolo de la soberanía nacional. En concreto, se estudian aquí gitanismos documentados en las ediciones del Catauro de Fernando Ortiz (1923, 1985) y se presta atención a cómo iba cambiando su presencia tanto en la macroestructura como en la microestructura de ambas ediciones. Se sostiene que estos datos lexicográficos podrían reflejar los cambios en la historia de esta parcela del léxico del español cubano, los avatares de la historia moderna de la isla y la evolución del sentimiento de la identidad nacional cubana.
\end{abstract}

Palabras clave: español cubano, gitanismos, lexicología y lexicografía históricas, historia e identidad.

* Para correspondencia, dirigirse a: Ivo Buzek (ibuzek@phil.muni.cz), Filozofická fakulta Masarykovy univerzity, Ústav románských jazykủ a literatur, Arna Nováka 1, 60200 Brno, Česká republika. 


\title{
The Gypsy loanwords included in Catauros by Fernando \\ ORTIZ AND THE STORIES THEY TELL
}

\begin{abstract}
The aim of the paper is to focus on mutual relations between various aspects of monolingual dictionaries that can be witnesses of history of vocabulary, a genre of pedagogical discourse or a symbol of national sovereignty. We will exemplify the study on the case of Gypsy loanwords testified in the two editions of the Catauro by Fernando Ortiz $(1923,1985)$, paying attention to changes suffered in their macrostructure as well as in the microstructure in both editions. We sustain that these lexicographic data could reflect the history of the Cuban Spanish vocabulary in the 20th century as well as the contemporary Cuban history in general and they could mirror the evolution of the Cuban identity.
\end{abstract}

Keywords: Cuban Spanish, Gypsy loanwords, historical lexicology and lexicography, history and identity.

Recibido: 25/01/16

Aceptado: 15/03/16

\section{INTRODUCCIÓN ${ }^{1}$}

Los diccionarios son repertorios que hacen posible una lectura e interpretación múltiples de los datos que ofrecen: son repertorios que pertenecen al discurso pedagógico e instruyen al usuario sobre el valor léxico-semántico, gramatical y combinatorio de determinadas palabras (Ruhstaller y Gordón 2010), son testimonios sociohistóricos y espejos de las sociedades que los han visto nacer (Lara 1997) y pueden servir, asimismo,

1 Una primera versión de este trabajo y muy reducida fue presentada como ponencia en el 55 ICA - Congreso Internacional de Americanistas (El Salvador, 12-17 de julio de 2015) bajo el título "Historia del léxico, diccionario e identidad a través del tiempo: el caso de los gitanismos en los Catauros de Fernando Ortiz".

Este artículo ha sido posible gracias al apoyo de la Facultad de Filosofía y Letras de la Universidad Masaryk. 
como fuentes documentales para la historia del léxico que albergan en sus columnas (Prieto 2014) ${ }^{2}$.

El objetivo del presente ensayo será estudiar la relación entre las posibles e inseparables facetas de los diccionarios utilizando como botón de muestra las palabras de origen gitano y agitanado (en el sentido de origen remoto) que se encuentran en las ediciones del Catauro de Fernando Ortiz (Un catauro de cubanismos, de 1923; y Nuevo catauro de cubanismos, de 1985). Prestaremos atención a cómo fue cambiando su presencia en ambas ediciones, tanto en la macroestructura, como en la microestructura, para saber qué datos aportan para la historia del léxico del español cubano durante el siglo XX y qué valores e informaciones (sociohistóricos, etnográficos o pedagógicos) le transmite el autor al usuario en el paso de una edición a otra.

Hemos seleccionado como objeto de estudio el léxico de origen gitano -origen remoto, como ya hemos dicho; aunque para el español de Cuba serían con mucha probabilidad españolismos- porque son generalmente palabras muy expresivas que varían de manera radical de una modalidad del español a otra y, a la vez, son voces sobre cuya historia, difusión, variación formal y semántica y una eventual pérdida en distintas variedades del español existe hoy día todavía poca bibliografía ${ }^{3}$. Han estado al margen del interés de los investigadores a pesar de que pueden aportar mucha información sobre la historia del léxico en general y sobre las relaciones entre el léxico y los diccionarios en particular (cf. Buzek 2013a).

Ahora bien, hablando de esta parcela del léxico cubano y de su representación en el Catauro de Fernando Ortiz hay que tener en cuenta, en primer lugar, que la obra nació como una contestación (constructiva) al Vocabulario cubano de Constantino Suárez, de 1921. Por tanto, este será un punto de partida obligatorio para cualquier consulta que le hagamos al Catauro, sobre todo a la edición de 1923, y es necesario tener presente este

2 La bibliografía sobre estos aspectos es abundantísima. Por tanto, para no sobrecargar el texto con una cantidad abrumadora de referencias que al fin y al cabo no servirían más para introducir y delimitar el tema, hemos optado por citar tan solo obras de reciente aparición y que incluyen a su vez una buena selección de bibliografía sobre el tema (Ruhstaller y Gordón 2010; Prieto 2014) o las que han marcado profundamente el nivel de conocimiento en el ámbito y siguen siendo una referencia obligatoria hasta hoy día (Lara 1997). Para más referencias, véanse los repertorios bibliográficos dirigidos por Ahumada (2006, 2009 y 2015).

Para los gitanismos en el español de España, véase Buzek 2010 y la bibliografía que allí se cita. Para los gitanismos en distintas modalidades del español en América, cf. Lara 1992; Buzek 2009, 2012, 2013b, 2013c, 2014a, 2014b y 2015. Podría haber más estudios de palabras sueltas en trabajos sobre el argot de la delincuencia en la América Latina. 
hecho para contextualizar adecuadamente todos los posibles aspectos de la obra.

Sin embargo, la información que aportan los diccionarios es auténtica y verosímil solo cuando estos están avalados con textos, y este aspecto no siempre queda explicitado (véase más adelante). Por ello, otro componente importante para nuestro estudio será la documentación textual complementaria procedente de textos cubanos de la época, que nos servirá para contrarrestar la subjetividad (consciente y querida) del autor comprobando así la veracidad y la autenticidad de informaciones y valores que le transmite la obra al público.

\section{MARCO METODOLÓGICO}

Según hemos apuntado más arriba en la introducción al artículo, nuestro propósito será averiguar qué información sobre la historia del léxico de origen gitano en la modalidad cubana del español nos trae Fernando Ortiz en las ediciones de su Catauro y cómo la contextualiza.

En lo que se refiere al marco metodológico general del trabajo, seguimos sobre todo los postulados de Luis Fernando Lara (1990, 1996, 1997 o 2004) en los que dice que los diccionarios de lengua son repertorios de consulta con una eminente función social e identitaria para sus comunidades de habla y, por tanto, deberían representar adecuadamente todos los matices lingüísticos del habla de dichas comunidades. De allí se desprende que cada diccionario debería apoyarse en una extensa documentación textual para poder ofrecer una imagen fidedigna de la realidad lingüística al público ${ }^{4}$.

Por tanto, los diccionarios de lengua que cumplen con estas condiciones pueden ser tomados no solo por unos repertorios de consulta útiles para su

4 Lara defiende con insistencia la necesidad de basar los diccionarios en textos para minimizar posibles desaciertos debidos a la subjetividad de los redactores $u$ otros factores externos que influirían de manera negativa en la impronta social de las obras en cuestión como sigue: "Cuando se desconocen los componentes y los límites de una forma de hablar, la construcción de un corpus de datos es la mejor manera de: (a) eliminar sesgos de elección, debida a la intervención de factores ideológicos, (b) reconocer un número elevado de elementos, (c) identificarlos cuantitativamente, (d) prover al lexicógrafo de datos de significado y uso reales, que permitan una definición lexicográfica original, (e) proverlo de ejemplos de uso reales" (1996: 22-23). 
comunidad de habla, sino que representan también unos corpus lexicológicos que dan fe de la realidad lingüística de una determinada lengua en el tiempo y en el espacio dados. Como dice Lara:

[L]os diccionarios cuentan en su documentación con datos extensos del léxico y, además, precisamente son sus diferentes criterios de selección del vocabulario manifiestos en sus productos, los que exponen con mayor claridad la complejidad del léxico hispánico contemporáneo. En ese sentido, los diccionarios son estudios lexicológicos, que no se limitan a la descripción del vocabulario, sino que lo interpretan dentro de su complejidad social (Lara 2004: 305).

Ahora bien, los postulados de Lara se refieren al Diccionario del español de México (2010) del que ha sido director. Es un diccionario sincrónico e integral del español mexicano y, por consiguiente, si hemos de aprovechar con éxito su armazón metodológico y aplicarlo a diccionarios con características distintas, habrá que llevar a cabo algunas modificaciones.

En primer lugar, trabajando con diccionarios antiguos muchas veces no estamos seguros de si estos han contado o no para su confección con una base textual sólida, con un "corpus". Ha habido diccionarios del español que sí se sustentaban en textos de manera sistemática y que tenían un plan editorial previo (el Diccionario de autoridades de la Real Academia Española, de 1726-1739; el Diccionario castellano del P. Terreros, 1786$1793^{5}$; u otros que analiza con detalle Prieto 2014); sin embargo, si hablamos de diccionarios diferenciales del español en América a finales del siglo XIX $\mathrm{y}$ en las primeras décadas del siglo $\mathrm{XX}$, en su caso se trataba más bien de colecciones de apuntes muy heterogéneos y la documentación textual, si la hubo, sería poco coherente y asistemática ${ }^{6}$.

Por consiguiente, en lo que se refiere al valor de los diccionarios de antaño como fuentes para la historia del léxico, estamos de acuerdo con Prieto cuando dice que "[c]onviene no olvidar que antes de la aparición de los corpus una de las herramientas filológicas principales con las que contaba el investigador del léxico eran los diccionarios, y especialmente los que avalaron sus voces y acepciones con textos" (2014: 196). Sin embargo, puesto

Ambos incluidos en el Nuevo Tesoro Lexicográfico de la Lengua Española de la Real Academia Española y disponibles en: http://ntlle.rae.es/ntlle/SrvltGUILoginNtlle [último acceso: 30.11 .2015$]$.

6 Véase, por ejemplo, lo que se dice al respecto en los prólogos de los diccionarios de Gagini (1893 y 1918), Ramos i Duarte (1895), Pichardo (1836) u Ortiz mismo (1923) (cf. Buzek 2013b, 2014b y 2015). 
que los autores de diccionarios antiguos no siempre avalaban sus voces y acepciones con textos y, como hemos dicho, no estamos seguros de si lo habían hecho antes a la hora de redactar sus obras, estamos convencidos de que para poder usar sus diccionarios como corpus, este trabajo de avalar las voces con textos lo tenemos que hacer nosotros, o sea, nos vemos obligados a consultar sus diccionarios "integralmente", es decir, acudiendo de manera sistemática a textos de la época para poder confirmar o poner en duda la información que traen los diccionarios en cuestión?

Aunque es probable que así cumpliríamos básicamente con los requisitos de la lexicología histórica, creemos que correríamos el riesgo de caer en una interpretación más bien mecanicista o documentalista del léxico si nos limitáramos tan solo a recoger datos sin explicarlos en su contexto sociohistórico. Como hemos dicho más arriba cuando hemos parafraseado los postulados de Lara sobre el valor social de los diccionarios, son obras con una función identitaria para sus respectivas comunidades de habla, y los diccionarios diferenciales latinoamericanos de finales del siglo XIX y de comienzos del siglo XX no son una excepción, aunque es cierto que podrían considerarse como casos que a veces tienen sus particularidades. Como dice Huisa Téllez (2014: 141-142):

[E]sta primera lexicografía [del español americano] surge en medio de un proceso de formación nacional, del que constituye finalmente una clara manifestación, lo que no solo explicaría el registro de elementos propios de un determinado país -los llamados -ismos-, sino también las características estructurales de los mismos diccionarios. [...] estos primeros diccionarios constituyen el resultado de un primer impulso patriótico, lo que se expresa directamente en sus páginas, no solo en las palabras preliminares sino también en el mismo cuerpo lexicográfico.

Más adelante comenta el investigador peruano que a la vez "debemos reparar en una clara formación identitaria que se lleva a cabo de la mano de una descripción filológica" que encontraría su proyección en el hecho de integrar elementos propios de la lexicografía de regionalismos y la frecuente inclinación enciclopédica de los diccionaristas (Huisa Téllez 2014: 142-143).

No obstante, también es preciso recordar que esta lexicografía regionalista y enciclopédica movida por exaltaciones patrióticas estaba condicionada por

\footnotetext{
Aunque en principio podría ser metodológicamente válido a nivel general, i.e. en referencia a la nomenclatura completa del diccionario en cuestión, reconocemos que por motivos prácticos es manejable tan solo con parcelas reducidas del léxico, como en nuestro caso.
} 
la procedencia criolla de clases medias y media altas de sus autores. Huisa Téllez (2014: 145) advierte que "si asumimos que los primeros lexicógrafos pertenecen a la elite cultural y económica de la sociedad postindependentista -en concreto, los criollos que heredan la administración colonial y el poder coercitivo-, está claro que los modelos que repetirán y difundirán a través de sus obras estarán claramente marcados por un sesgo ideológico propicio para ella"s.

Este hecho más tarde llevaría a la fundación de las academias latinoamericanas de la lengua correspondientes de la española y perpetuaría el colonialismo lingüístico - que en la lexicografía se manifiesta en la continua publicación de repertorios de -ismos- hasta hoy día (cf. Senz 2011; Lara 2011; o Zimmermann 2003 y 2012).

Ahora bien, el caso de los Catauros de Fernando Ortiz es muy particular, puesto que son obras publicadas después de las que hoy día suelen ser objetos de estudio de los investigadores de la historia social del español en América y de sus diccionarios. La edición de 1923 está condicionada por la situación histórica de la isla durante las primeras dos décadas del siglo XX, mientras que la segunda fue terminada cuatro décadas más tarde y publicada como póstuma en 1985, cuando el contexto sociohistórico cambió radicalmente.

En resumidas cuentas, sostenemos que en lo que se refiere a la metodología utilizada en el presente trabajo para el estudio del léxico de origen gitano en las ediciones del Catauro de Fernando Ortiz podemos, en principio, aprovechar con modificaciones el armazón metodológico ideado por Lara para las necesidades del Diccionario del español de México, siempre y cuando avalamos las voces en cuestión con textos ${ }^{9}$, y prestamos atención a la vez al contexto sociohistórico, como advierten Huisa Téllez y otros autores citados más arriba. Ahora bien, creemos que los Catauros de Ortiz tienen a la vez otros aspectos de interés añadidos. En particular,

\footnotetext{
8 La historia social del español en América a través del prisma de los repertorios léxicos diferenciales es un tema vigente y se está trabajando en él (véanse, por ejemplo, los trabajos de Lauria 2011, 2013a y 2013b; Coll 2012 y 2013; Chávez Fajardo 2011 y 2012; o Huisa Téllez 2011 y 2013, entre otras posibles referencias).

9 Como también ya hemos apuntado más arriba, una metodología similar, aunque orientada hacia la historia de los neologismos acuñados por Tirso de Molina y su presencia en diccionarios monolingües del español, ha sido utilizada por Prieto 2014, que argumenta que su metodología - utilizar un léxico bien definido como botón de muestra- podría servir a la vez para los fines de la crítica lexicográfica, en el sentido de saber cómo evaluar la aportación original de los diccionarios -antiguos y nuevos-, es decir, si están basados en textos originales, si dependen exclusivamente de diccionarios publicados antes o cuál es la proporción (en términos de probabilidad y de manera muy aproximada, sobre todo en casos de los diccionarios antiguos) entre ambos procedimientos del quehacer lexicográfico.
} 
serían los de la evolución del diccionario como una obra con función social e identitaria en un diccionario con función documental y etnográfica, como veremos a continuación.

\section{LAS EDICIONES DEL CATAURO DE FERNANDO ORTIZ: MACROESTRUCTURA, MICROESTRUCTURA Y CONTEXTO SOCIOHISTÓRICO}

Puesto que la obra lexicográfica de Fernando Ortiz ya ha sido objeto de varios estudios, tanto de los que han interpretado diversos rasgos de su macro y microestructura en un contexto más amplio (Camacho Barreiro 2003-2004, 2008 y 2009), como de los que se han centrado en los aspectos idiosincrásicos (internos y externos) de la lexicografía del autor cubano (Camacho Barreiro 2000 y Fay 2010), creemos que no es necesario volver a repetir cosas consabidas y que podemos centrarnos sin más demora tan solo en aquellas características que son de suma importancia para nuestro estudio. En este, como ya hemos advertido más arriba, manejamos los Catauros como fuentes documentales sociohistóricamente contextualizadas para la historia del léxico del español en Cuba, limitado aquí a la historia de voces de antiguo origen gitano. En lo que atañe a su macroestructura, nos centraremos con prioridad en la procedencia de las voces lematizadas y en las condiciones externas que podían haber influido en su elección; en la microestructura prestaremos atención a la definición y a las demás informaciones relacionadas con la restricción del uso, igual que a los ejemplos, si los hay.

Como también ya hemos apuntado más arriba, la edición de 1923 del Catauro tiene origen en una serie de artículos polémicos - pero en un sentido positivo- dirigidos al Vocabulario cubano de Constantino Suárez (1921) y publicados en la Revista Bimestre Cubana durante los años 1921 y 1922.

En lo que se refiere a la base en la que se sustentaba el Vocabulario de Suárez, este reconoce haber manejado fuentes muy variadas (1921, VIIXXIV): el diccionario de Esteban Pichardo; el "Nuevo Apéndice O-Z", tomo XXVIII del Diccionario enciclopédico hispano-americano, de Montaner y Simón; el DRAE-1914; Lexicografía antillana, de Alfredo Zayas; el Pequeño Larousse Ilustrado; el Nuevo diccionario de la lengua castellana, de Vicente Salvá; Apuntes sobre el lenguaje bogotano, de Rufino José Cuervo; El castellano en Venezuela, de Julio Calcaño; el Vocabulario criollo-español, sud-americano, de Ciro Bayo; y anotaciones propias, muy probablemente 
asistemáticas y heterogéneas que, según apunta Suárez, forman más de un $25 \%$ del total (1921, XXIII), dato que no hemos podido verificar.

No obstante, sería erróneo pensar que Ortiz se limitara en la nomenclatura del Catauro tan solo a reproducir -total o parcialmente- la de Suárez y a comentarla. La aportación original de Ortiz es evidente desde el principio, como puede leerse en el prólogo a la obra (1923: VII):

Nació la idea de recopilar en un CATAURITO cubanismos y apuntaciones lingüísticas, al leer un valioso vOCABULARIO CUBANO y analizarlo para las notas bibliográficas de aquella revista; $y$ en él pusimos algunos frutos de la tierra, que habíamos recogido cruzando la selva del lenguaje criollo en busca paciente de raíces y flores traídas y arrojadas al azar por los esclavos africanos, mientras tumbaban monte en nuestra isla para siembra de cañas y cafetos; y otros de muy diverso aporte con que tropezamos en nuestras correrías por campos y playas de Cuba.

En lo que refiere a las áreas concretas de anotaciones críticas, comenta Camacho Barreiro (2000: 270-271) que:

Ortiz saluda con entusiasmo la obra de El Españolito y la valora como "recomendable". En su artículo "El nuevo catauro de cubanismos" se acerca críticamente a algunas de sus deficiencias, tales como la inclusión indiscriminada de voces jergales del hampa, “....de carácter sumamente transitorio..." (Ortiz 1985: 18) o el abordaje etimológico inexacto de ciertas voces, terreno que califica de "inseguro y movedizo". Sin embargo, el propio Ortiz no pudo sustraerse a dicho abordaje y de igual forma incurrió en errores, desaciertos y fantasías.

El Vocabulario de Suárez se presenta al lector como "Suplemento a la $14^{\mathrm{a}}$ edición del Diccionario de la R. A. de la Lengua", como se puede leer en la portada, es decir, como mera colección de -ismos pintorescos, mientras que el Catauro de Ortiz debería interpretarse en un contexto histórico y social mucho más complejos ${ }^{10}$. Advierte Fay (2010: 44) que “[u]nlike Suárez, Ortiz

10 Aunque es cierto que también el Catauro de Ortiz (junto con otra compilación lexicográfica de su autoría, el Glosario de afronegrismos) llegó a aumentar el filón de cubanismos en el Diccionario de la Corporación. Reproduce Camacho Barreiro (2000: 271) un fragmento de una carta de Ortiz dirigida a Chacón y Calvo en la que Ortiz escribe: "Me encanta saber que habrá de contribuir [...] a la académica reivindicación de los plátanos fritos. ¡Lo merecen!" Explica Camacho que “[e]ste júbilo está motivado por el interés que le manifestó Ramón Menéndez Pidal de aprovechar 'el jugo' de ambos volúmenes en la conformación de la $15^{a}$ edición del Diccionario de la Real Academia de la Lengua Española" (2000: 271). 
does not offer a supplement to the Academy's authoritative lexicography nor a re-reading of the Americanisms at the edge. Instead, the Catauro is a fundamental re-articulation of the Spanish language from within the idiomatic, idiosyncratic, and fundamentally archipelagic frontiers of the Cuban condition".

Como es bien sabido, aunque el Catauro apareció ya en la época de la independencia, esta no fue una independencia con pleno derecho, y el intervencionismo militar y económico de los EE.UU. en los asuntos internos de la isla era constante. El descontento de la población con la corrupción extendida se iba radicalizando hasta desembocar en 1923, el año de la publicación del Catauro, en una serie de sucesos históricos y sociales de mucha importancia para la posterior historia de la isla (Fay 2010: 46-48). Fay interpreta el Catauro como una especie de manifiesto de la soberanía en el uso de la lengua, como una reivindicación del derecho de ser autónomo e independiente no solo en aspectos políticos, sino también en los lingüísticos "[b]ut equally imperative was Ortiz's lexicographic battle for the right to describe Cuba in Cubanisms; the right to speak of, as, and to el pueblo cubano. [...] Ortiz's Catauro is as much a metaphoric as a lexicographic guide to cubania in the early 1920s" (2010:48).

No cabe ninguna duda de que el Catauro sea un texto polémico y argumentativo y de que deba ser interpretado en el contexto de la época. Nosotros, a su vez, lo leemos como un diccionario monolingüe y diferencial redactado con el ánimo de mostrar con orgullo las peculiaridades del uso del léxico cubano y que, a pesar de todas las condiciones específicas de su contexto histórico y cultural, es un corpus lexicológico que aporta datos lingüísticos sobre el léxico de su tiempo.

Ahora bien, a pesar de que la nomenclatura estaba muy probablemente respaldada por el uso -y no tenemos ninguna razón, salvo prudencia debida, para poner las afirmaciones de Ortiz en duda-y sería, por tanto, auténtica y fiable, en cuanto a la ordenación y presentación de los materiales, el Catauro de 1923 es, como mínimo, incoherente. Según las palabras de una de las colaboradoras más cercanas de Ortiz - citadas por Camacho Barreiro (2000: 272)-, " "[p]or un inexcusable error de emplanamiento tipográfico se publicó sin contar con un orden alfabético que guiara al lector por el intrincado mar de 'cubicherías' que contiene. Esto imposibilitó a más de un estudioso la consulta fructífera del texto (Martínez 1967: 173)". Para la edición póstuma de 1985 los artículos ya seguían la ordenación alfabética habitual.

En lo que se refiere a la edición póstuma de la obra y a la evolución de su valor sociocultural para la sociedad cubana durante el siglo XX, creemos que a pesar de que Ortiz seguía hablando de "cubicherías", el término en la segunda mitad del siglo XX ya estaba despolitizado y no tenía ningún 
matiz de reivindicación nacional contra las fuerzas (neo)colonizadoras. Se trataba más bien de proponer soluciones a problemas metodológicos relacionados con el valor etnográfico de las voces coleccionadas y la información que se ofrecía sobre su uso, es decir, cómo aplicar unos métodos etnográficos modernos desarrollados para civilizaciones "madres" en una sociedad postcolonial (Los editores ${ }^{11}$ 1985: 9): "La tarea era doble: ponerse a una misma altura metodológica tratando, simultáneamente, de localizar el verdadero cuerpo de la cultura cubana, todavía y por mucho tiempo confuso dado el lento proceso de descolonización frenado por un proceso, a contrapelo, de colonización que adoptaba otras variantes".

En cuanto a la microestructura, tiene razón Camacho Barreiro (2000: 271-272) cuando dice que es arbitraria y desorganizada. La información que aporta no está estructurada como es habitual en los diccionarios de lengua y los datos hay que extraerlos del conjunto del texto de cada artículo. Más que de artículos lexicográficos cabría hablar de microdiscursos en torno a la etimología y al área de uso de determinadas palabras consideradas por Ortiz típicamente cubanas que en su opinión tenían para los habitantes de la isla en el momento de la redacción de la obra un especial valor afectivo o hasta identitario.

Para más información sobre la microestructura de ambas ediciones del Catauro, véanse los estudios de Camacho Barreiro que citamos: en el trabajo sobre la labor lexicográfica de Ortiz (Camacho Barreiro 2000) se ofrece, entre otras informaciones, una clasificación tipológica de definiciones que Ortiz había ensayado en sus obras -hay que mencionar expresamente que con razón la investigadora no habla de "definiciones" sino de "indicaciones o explicaciones lexicográficas"-; en el trabajo de 2003-2004 habla sobre las huellas ideológicas; en el de 2008 sobre el valor de sus marcas sociolingüísticas; y en el de 2009 analiza el valor de los ejemplos. Son observaciones muy acertadas para tener una visión de conjunto de la obra, sin embargo, puesto que la muestra que manejamos aquí es muy reducida, y dado que las microestructuras de ambas ediciones del Catauro son muy variadas y están lejos de ser uniformes y coherentes, tal y como esperaríamos de un diccionario normal y corriente, no vamos a extendernos aquí más hablando sobre la microestructura en general y guardamos posibles observaciones para más tarde cuando hablemos de casos concretos.

11 La edición póstuma del Nuevo catauro está precedida por una "Nota a la edición", de autoría colectiva, firmada por "Los editores". Puesto que ignoramos quiénes fueron los autores de la nota, los citamos tal como habían firmado el texto. 


\section{GITANISMOS EN LAS EDICIONES DEL CATAURO}

A continuación presentamos la parte central de nuestro trabajo. Se trata de un estudio detallado de voces gitanas y agitanadas -ambas en el sentido de un étimo remoto, como ya hemos apuntado más arriba-. En cuanto a su procedencia inmediata, serán españolismos, puesto que como hemos comprobado en Buzek 2010, finales del siglo XIX y comienzos del siglo $\mathrm{XX}$ fue la época crucial para la entrada y propagación de gitanismos en el español europeo que de allí se fueron difundiendo (de manera desigual y condicionados por diversos factores externos y sociohistóricos) a las variedades latinoamericanas del español.

Como también ya hemos dicho más arriba y como ya hemos constatado en nuestros trabajos previos sobre el tema, las cifras de gitanismos en los diccionarios del español en América son más bien modestas y los Catauros de Ortiz no son en este aspecto ninguna excepción; sin embargo, los datos que traen son de sumo interés para la historia del léxico.

Después de leer atentamente ambas ediciones de la obra y de contrastar su nomenclatura con trabajos dedicados al léxico de origen gitano en otras modalidades latinoamericanas del español (Lara 1992; Buzek 2009, 2012, 2013b, 2013c, 2014a, 2014b y 2015) hemos entresacado de sus páginas doce palabras en total: manganzón, mangar, manguindó, mangón, mangado, paripé, sandunga, sandunguear, sandungueo, sandunguería, sandunguero y tajaleo. Por supuesto, sería ilusorio intentar formular a partir de una muestra tan reducida unas conclusiones generales. No obstante, las voces y la evolución de su tratamiento ilustran muy bien cómo ha ido cambiando su valor social durante el siglo XX. Son testigos del cambio de su función identitaria, de la naturaleza de su "cubanidad" y de su valor etnográfico, según la visión particular de Fernando Ortiz.

Aplicaremos aquí por tanto la tesis de Lara sobre el valor social de los diccionarios en relación con el léxico que albergan en sus columnas, adaptada a la realidad del tipo de léxico y a las particularidades del diccionario en cuestión, tomando a la vez en consideración la proyección histórica de nuestro estudio (en términos de Prieto 2014) y el trasfondo sociohistórico y sociocultural de la obra (Huisa Téllez 2014, entre otros autores citados más arriba).

En los apartados que siguen intentaremos ilustrar los fenómenos de cambios de perspectiva, comparando las explicaciones lexicográficas de ambas ediciones, analizando sus contenidos e interpretando los datos que aportan como testimonios de la evolución del léxico del español cubano. 
Si no hay diferencias en el tratamiento entre la edición de 1923 y la de 1985, citamos solo la primera, indicando el número de página. Otro aspecto importante de nuestro trabajo serán las documentaciones textuales que procuramos aportar para cada palabra estudiada para dar prueba de licencia de lo que dice Ortiz.

\subsection{MANGANZÓN}

MANGANZÓN, NA. adj. -Holgazán, vago, zangolotino. Es una de tantas voces heredadas de los portugueses. En el lenguaje lusitano mangar es 'burlarse de uno', mangacao [sic] es 'burla', maganao 'tunantear', magano 'tuno', 'pillo. El vocablo corre por toda América (Catauro 1923, 262)

Como explicaremos a continuación, estamos convencidos de que manganzón derivó en principio del caló mangar 'pedir, mendigar' (cf. Buzek 2010: 164-165; Krinková 2013: 230; y Krinková 2015: 240) ${ }^{12}$. Como podemos leer en la explicación, Ortiz hizo todo lo posible (e imposible) para dar con un étimo portugués, pero por razones históricas es más probable que provenga del gitano.

Suárez (1921) recoge la voz también remitiendo a un posible parónimo pero la información que ofrece en total es confusa y contradictoria:

Manganzón, na. Amer. adj. -Véase mamalón, na.

Mamalón, na. Cub. adj. -Se aplica a la persona holgazana y robusta que gusta de vivir sin ganarlo, pero sin declararse amiga de lo ajeno. En otros puntos de América se dice manganzón, na, usado en Cuba.

Para la documentación textual, véase la siguiente copla:

Mi mujer el otro día, me dijo muy afligida

Que pa' hacerme la comida, ella leña no tenía

Me dijo mil boberías, no seas tan manganzón

Tráeme leña o carbón tú, conmigo no seas malo

Y entonces le eché...

12 En el caso de las acepciones latinoamericanas de mangar y sus derivados existe todo un entramado de formas homónimas y parónimas con propuestas de etimologías a veces extravagantes (DCECH: mandinga y magancés; Cuervo 1907: 557) entre las que la "vía gitana" parece ser una de las más modestas. 
tres palos de leña dentro el fogón

(Oramas 1968).

\subsection{MANGAR}

MANGAR. Engañar. 'Lo mangué con mucha facilidad' (Nuevo catauro 1985).

No se documentaba en la edición de 1923, sino tan solo en la de 1985.

La procedencia gitana de mangar está bien estudiada y documentada. En el caló significaba 'pedir, mendigar', y en el español europeo desarrolló el significado 'hurtar, robar' (Buzek 2010: 164-165). La extensión del significado del original gitano 'pedir, mendigar' a través del peninsular 'hurtar, robar' al cubano 'engañar' cabe muy bien dentro del patrón del cambio semántico en hablas marginales, aunque a falta de documentación Corominas y Pascual aconsejan obrar con prudencia (cf. DCECH, mandanga).

En lo que se refiere a la documentación cubana de la voz, hemos encontrado un ejemplo en el texto de una copla de la época de Ortiz; sin embargo, como el significado allí no está del todo claro, hemos decidido buscar un segundo ejemplo, aunque sea contemporáneo.

El que ve la lechuza de momento

la quiere mangar,

pero yo que conozco el elemento

guapachá, guapachá.

Buchipluma na más, eres tú

(Hernández 1957).

No será menester juzgar con dureza excesiva a los crédulos, esperanzados o incautos que ahora marchan directos a dejarse mangar por quienes inflan la burbuja

(Fernández s.a.).

\subsection{MANGUindó}

MANGUINDÓ. Holgazán. Suárez la da por voz africana, pero es gitana según F. M. Pabanó, Rebolledo y otros gitanólogos. En caló significa 'interesado', 'pretendiente' y derívase de mangar 'pedir', 'mendigar'. (Nuevo catauro 1985) 
En la edición de 1923 no tenía un lema independiente, sino que se hallaba en el interior de otro artículo: "Manguindó, en cambio, no es africana como dice [Suárez], sino gitana, como furnia, giribilla y otras que corren en Cuba ${ }^{13}$; ni lo son mangón y mangado" (1923: 13). El artículo original de Suárez era este: "Manguindó. Cub. m. -fam. -Dícese al individuo holgazán (Et. Voz africana)".

En lo que se refiere a la etimología, es cierto que en los diccionarios del caló de Pabanó (2007 [1915]) y de Rebolledo (2006 [1909]) encontramos la forma manguindón 'interesado, pretendiente' que no está del todo alejada del étimo original gitano. Ahora bien, Corominas y Pascual ponen la etimología gitana en duda cuando dicen que no hallan "asideros firmes para tal supuesto en las fuentes gitanas a [nuestro] alcance" (DCECH, mandanga). Pero como la posibilidad de la etimología gitana no se puede desechar del todo, la admitimos con cierta reserva y con debida precaución.

Desafortunadamente, no hemos encontrado ningún ejemplo, ni en los corpus, ni en el internet cubano ${ }^{14}$. No obstante, en el Fichero General de la Real Academia Española ${ }^{15}$ hemos encontrado varias fichas, pero todas son de carácter lexicográfico y dependen de la obra de Ortiz.

\section{4. (MANGADO Y MANGÓN)}

Estas dos voces no aparecen en el Catauro como lemas pero como hemos visto en el subapartado anterior, en la edición de 1923 se citan en el texto de otro artículo sin ser definidas: "Manguindó, en cambio, no es africana como dice [Suárez], sino gitana, como furnia, giribilla y otras que corren en Cuba; ni lo son mangón y mangado" (1923: 13). Por el contexto de la cita y por la forma suponemos que se tratará de derivados de mangar 'engañar'.

13 Hemos localizado furnia en el diccionario de caló de Pabanó (2007 [1915]), con la grafía furniá 'cavidad, cueva'; giribilla, a su vez, la encontramos en la forma no derivada y con la grafía jiribí y definidas como 'astucia, penetración, sagacidad' en Pabanó (2007 [1915]) y como 'astucia, sagacidad' en el diccionario del caló de Rebolledo (2006 [1909]). Ahora bien, el hecho de que una voz se halla en los diccionarios de caló no implica que sea un gitanismo, según hemos demostrado en Buzek 2011. Por tanto, y por no tener más información etimológica disponible sobre estas dos voces, optamos por excluirlas del estudio.

14 Hemos restringido las herramientas de búsqueda de Google al español y al área de Cuba.

15 Disponible en http://web.frl.es/fichero.html [última consulta: 30.11.2015]. 
En cuanto a la documentación textual, en el internet cubano hemos localizado solo contados ejemplos de formas verbales compuestas del verbo mangar. En el Diccionario de americanismos (DA) de la Asociación de Academias de la Lengua Española hemos encontrado como lema tan solo una forma en femenino mangada 'estafa, engaño', con la marca geográfica de Cuba y etiquetada como obsolescente. Desgraciadamente, no hemos encontrado ningún ejemplo real.

En lo que se refiero a mangón, en el DA encontramos el cubanismo 'hombre atractivo', sin ninguna otra restricción de uso. Sin embargo, como no hemos encontrado ninguna documentación textual cubana que pudiera corresponder a este significado, no podemos aportar más información.

\subsection{PARIPÉ}

PARIPÉ, m. -Simulación, acto hipócrita. 'Hizo el paripé de quererla.' 'Hizo el paripé que se suicidaba' (Catauro 1923, 264).

Es una voz con procedencia gitana comprobada (Buzek 2010: 183) y contamos para ella con varios ejemplos cubanos modernos.

Lo reciben, hacen el paripé de algunas medidas, que él tenía que estar bajo control, y allá está en Miami participando también, de una forma o de otra, en actividades terroristas.

(CREA: Oral s.a.)

Aunque suena popular, el término está aceptado por la Real Academia de la Lengua. También en Cuba, naturalmente, paripé es el ademán de, la pose de la acción, la figuración -por utilizar una palabra esbelta-. Hacer el paripé de algo, es hacer como que se hace el algo verdaderamente. Es simular, imitar, parecer.

(Rivero 2013)

Cabe preguntarse por qué Ortiz descatalogó el término de la segunda edición del Catauro. Creemos que fue por el hecho de ser una palabra que no es privativa de Cuba, sino que está compartida también con otras modalidades, como nos enseña el segundo ejemplo cubano contemporáneo. Puede que Ortiz haya ignorado este hecho cuando preparaba la primera edición. 


\subsection{SANDUNGA}

Sandunga. -Gracia, donaire. Es también andalucismo. Pero si no queremos inventariar como cubanismo este vocablo, ni tampoco sandunguero, sí debemos hacerlo con sandungueo, sandunguería y sandunguear, que no hemos hallado en diccionario alguno. Hoy está ya sandunga admitida como voz del Diccionario de la Academia (Catauro 1923: 23).

Según hemos mostrado en nuestro estudio monográfico sobre los gitanismos en el español europeo, se trata de una voz de oscura historia, más agitanada que genuinamente gitana (Buzek 2010: 206-207). Según advierten Corominas y Pascual, es "voz familiar y semi-jergal, de origen incierto, quizá gitano" y "[t]odos sabemos que es palabra agitanada o flamenca" (DCECH, sandunga, 150).

Disponemos de varios testimonios de la voz:

-¡Siá! ¡Que no se ajuma, que no se ajuma!... -exclamó la Caliente prosiguiendo su camino con sandunga provocativa y riendo a carcajadas (CORDE: Bobadilla 1903).

Aquella sandunga es la afrocubanía musical de los días coloniales, africanía que se contoneaba medrosa y no se confesaba negra ni mulata; se decía sólo "criolla", era criolla "pasá

(CREA: Ortiz 1975).

Al compás de la música, las jóvenes en el zaguán cantaban el siguiente estribillo: Me abraza como una lava la sandunga de esta danza ¿y qué cosa no se alcanza en tocando la ley brava?

(CREA: Évora 1997).

También en este caso creemos que Ortiz la descatalogó de la segunda edición porque no la consideraba propiamente cubana -como se desprende de la explicación de la voz ya en la edición de 1923- y no tenía para él, por tanto, el valor etnográfico.

\subsection{SANDUNGUEAR}

SANDUNGUEAR. Actuar con sandunga. Conducirse con sandunga. 'Iba sandungueando.' Femenino. Gracia, donaire, salero. Así dice el diccionario de la Academia. La voz ndunga significa una clase de 
tambores o cierto instrumento musical de Congo. ¿Sería la gracia o 'sal' africana de éste lo que produciría en Andalucía, y luego en Cuba, el uso de la voz sandunga? ¿Sería de sal ndonga, o 'sal de Angola'? Rafael Salillas la incluye entre las voces del caló gitano, lo cual no impide que pueda ser de oriundez africana. Creemos que procede de Congo y no de ndunga 'cierto tambor', sino de ndungu 'pimienta' y 'picante'. El vocablo, muy común entre los congos, con varias acepciones derivadas, debió de introducirse en Andalucía por los esclavos congoleños. Véase lo que decimos en la voz mondongo. Entonces si de una mujer salerosa pudieron allá decir que tenía 'sal' o 'sa', de la hembra de muchísimo salero, y más si era mulata, pudiera pensar que tenía 'sa' y ndungu, o sea sa + ndungu, o, en castellano picaresco 'sal' y 'pimienta' (Nuevo catauro 1985).

La voz no tenía entrada propia en la edición de 1923, sino que se hallaba dentro de la de sandunga. En este caso, Ortiz sí la consideraba cubana y, por tanto, le dio entrada independiente.

Resume Ortiz en el texto una de las propuestas etimológicas de la voz que se cita también en el DCECH pero en opinión de sus redactores "no es verosímil desde el punto de vista geográfico, ni será posible tal yuxtaposición híbrida mientras no se prueba que un derivado de ndungu se ha empleado en castellano, por lo menos en el de los negros (en Cuba sandunga vale lo mismo que en España [...])" (DCECH, sandunga, 151).

Se documentan varios ejemplos en el internet cubano:

Su principal aspiración ahora es cantar y está dispuesto junto al grupo a llegar a donde quiera que lo soliciten, para que sepan que hay Indio Angá para rato y que todos los que asistan a los conciertos vayan preparados para sandunguear de lo lindo

(Valdés Alonso 2014).

\subsection{SandungueO}

SANDUNGUEO. Acción y efecto de sandunguear (Nuevo catauro 1985).

Es un caso similar al anterior. En la edición de 1923 estaba integrada la voz en el artículo de sandunga y según la opinión de Ortiz se trataba de un cubanismo de pleno derecho. Por tanto, en la edición de 1985 llegó a ocupar una entrada propia. Tenemos varios ejemplos para ilustrar el uso cubano de la voz. 
Alabado, negra, ¿de dónde te robaste ese sandungueo?

(CORDE: Carlos Felipe 1949).

La historia de Cuba está en el humo de su tabaco y en el dulzor de su azúcar y también está en el sandungueo de su música

(CREA: Ortiz 1975).

\section{9. (SANDUNGUERÍA Y SANDUNGUERo)}

En la edición de 1923 aparecían ambas voces en el cuerpo del artículo de sandunga, pero quedaron descatalogadas de la edición de 1985. En 1923, Ortiz reconocía la cubanidad de sandunguería pero se la negaba a sandunguero -con razón, hay textos españoles en los corpus académicos en los que se documenta la voz-. Para la edición de 1985 cambió de opinión y optó por excluir también sandunguería, aunque no sabemos muy bien por qué. La voz falta en los corpus académicos pero hemos localizado textos cubanos que la avalan.

Esa síntesis de sandunguería y protesta social, de externidad descriptiva e intimidad desolada va a convertirse en sello de la mejor poesía negrista del autor que tiene su expresión culminante en uno de los momentos más altos de la lírica criolla, las tantas veces citada Elegía de María Belén Chacón

(Castellanos y Castellanos 1994: 174).

No obstante su humor y su sandunguería callejera, "Ponle fe" es un reto deslumbrante que invita al oyente a adentrarse en un mundo de rituales, objetos ceremoniales, ofrendas, toda una economía o infraestructura de las religiones afro

(West-Durán 2009: 70).

¿Quié hizo a ña Dolly tan sandunguera y tan namorá?

(CORDE: Carlos Felipe 1949).

El supuesto "ciboneyismo", el "cucalambismo", no es sino criollez mestiza, realmente mulata y sandunguera

(CREA: Ortiz 1975).

A través del baile Cuba y el resto de las Américas inocularon a España la jácara y el meneo sandunguero

(CREA: Évora 1997). 


\subsection{TAJALEO}

Tajaleo. -Como dice Suárez, aplícase festivamente a la comida. ¿Por las tajadas? Pero el vocablo tiene un rancio sabor castizo. Tajadores se decía a los platos trincheros en tiempos del Arcipreste de Hita (Libro de Buen Amor, coplas 1252 y 1399) (Catauro 1923: 180).

TAJALEO. Como dice Suárez, aplícase festivamente a la comida. 'Llegó la hora del tajaleo'; 'El tajaleo está en la mesa.' ¿Por las tajadas? Pero el vocablo tiene un rancio sabor castizo. Tajadores se decía a los platos trincheros en tiempos del Arcipreste de Hita (Libro de Buen Amor, coplas 1252 y 1399) (Nuevo catauro 1985).

Es una palabra con una etimología oscura pero es probable que se trate de una voz derivada, con variación en la vocal pretónica, de tajelar 'comer', palabra con etimología mixta en cuya génesis habrá intervenido también el caló (Buzek 2010: 209-210).

Si comparamos la estructura de los artículos de ambas ediciones de la obra notamos que la única diferencia son los ejemplos. Estos provienen del Vocabulario de Suárez (1921): "Tajaleo. Cub. m.-fam. -Dícese festivamente a la comida; 'Llegó la hora del tajaleo'; 'el tajaleo está en la mesa'”.

Según afirma Camacho Barreiro (2009: 41), los ejemplos en los Catauros "son fruto de la inventiva del autor", sin embargo, en este caso, los ejemplos están tomados del inventario de su predecesor.

Suárez también había recogido otra acepción cubana, pero esta se registra en un artículo independiente: "Tajaleo. Cub. m. -fam. -Confusión, escándalo, pendencia: 'Se armó el gran tajaleo'".

Esta fue ignorada por Ortiz y probablemente con razón, ya que no hemos encontrado ninguna documentación textual para ella. Sí hemos encontrado un texto para avalar la acepción de 'comida':

En cuanto sobre La Habana

descarga un fuerte aguacero que el polvo de nuestras calles transforma en lodo al momento veréis surgir de improviso, como llovido del cielo, y enviado desde la altura por el celestial portero a este mozo bien fornido y de complexión muy recia que en lugar de cargar fardos 
o de machucar el hierro

se aplica a vender paraguas

con el honrado propósito

de buscarse tajaleo

(Barnet 2001: 140).

\section{CONCLUSIÓN}

Como hemos dicho al principio del trabajo, su objetivo principal ha sido poner en prueba el valor documental de los Catauros de Fernando Ortiz y manejarlos como fuentes para la historia del léxico de origen gitano en el español de Cuba durante el siglo XX en su complejidad social. En lo que se refiere a la evolución de los marcos sociohistóricos de la obra, de la edición de 1923 a la de 1985, estamos de acuerdo con la interpretación que proponen los investigadores que se han ocupado de ellas, cada uno por su cuenta: Fay (2010) propone leer la edición de 1923 del Catauro como un manifiesto de la soberanía lingüística, del derecho de describir Cuba en cubanismos, mientras que los editores del póstumo Nuevo catauro, de 1985, hablan más bien del valor etnográfico del caudal léxico que encierran sus páginas. Si aceptamos la hipótesis de que Ortiz cambió la óptica de la obra, desde el enfoque nacionalista al etnográfico, entendemos mejor algunos cambios que hemos notado en la parcela del léxico estudiado en el paso de una edición a la otra.

En primer lugar, hay voces de antiguo origen gitano que Ortiz reconoce como típicas y propias del español cubano y su opinión queda avalada, asimismo, por la documentación textual paralela y complementaria que hemos aportado por nuestra cuenta. Se trata de las voces manganzón y tajaleo.

Otro grupo lo forman las voces que no figuraban como lemas en la primera edición, unas tal vez por omisión (mangar) y otras porque se hallaban en el interior de otros artículos (sandunguear y sandungueo). Todas ellas cuentan con documentación textual. Para Ortiz son voces cubanas con valores identitario y etnográfico a la vez.

Otras las comparte el español cubano con otras modalidades regionales de la lengua -la mayoría se recoge asimismo en el DRAE-y, por tanto, fueron desalojadas de la edición de 1985 a pesar de contar con textos cubanos que las avalaban (sandunga, sandunguería, sandunguero y paripé). 
Y finalmente, tenemos palabras que no hemos podido documentar y que a su vez presentan evoluciones dispares: una de ellas se hallaba en la edición de 1923 mencionada en el texto y en la de 1985 consiguió entrada propia (manguindó), mientras que en otras dos ocasiones se trataba de voces que en 1923 aparecían también en la microestructura pero quedaron descartadas (por razones que ignoramos) de la edición de 1985 (mangón y mangado). Como en estos tres casos no disponemos de documentación textual complementaria, no nos queda más remedio que confiar en el instinto y en la competencia lingüísticos de Ortiz de que son voces que durante el siglo XX o cayeron en desuso, o las encontró Ortiz en otras modalidades del español también y perdieron, por tanto, cualquier interés (etnográfico) para él.

Puesto que Ortiz concibió la obra como un manifiesto de soberanía idiomática que con el paso del tiempo se convirtió en un catálogo etnográfico, faltan en ella por regla general voces jergales por ser, según la opinión del autor, "de carácter sumamente transitorio que son al idioma, más que hojas de su esplendoroso follaje, parásitos de su savia" (Ortiz 1985: 18). Esto también ayudaría a explicar por qué se encuentran en general tan pocos gitanismos en la obra, puesto que según hemos visto en nuestro estudio sobre los gitanismos en el español europeo (Buzek 2010), una gran parte de ellos pertenecía en principio a la jerga de la delincuencia y tradicionalmente han sido más bien voces propias del ámbito urbano.

Por tanto, las voces recogidas por Ortiz tienen el valor de ser testimonios de la propagación de antiguas voces gitanas desde el ámbito bajo urbano al español popular cubano en su sentido más amplio posible.

\section{ADDENDA. OTROS GITANISMOS EN EL VOCABULARIO DE SUÁREZ (1921)}

Suárez en su Vocabulario recogió otros gitanismos que, no obstante, no fueron incorporados en los Catauros de Ortiz, tal vez por falta de "cubanidad" con valor identitario y etnográfico y también por el hecho de ser a veces voces jergales "de carácter sumamente transitorio" (Ortiz 1985: 18), en opinión del autor, como ya hemos apuntado. En este aspecto, Ortiz se muestra más prescriptivo y censurador de lo que se esperaría de él, puesto que les niega el valor identitario y la función etnográfica a voces jergales y malsonantes. En la mayoría de las ocasiones se trata de palabras que ya hemos estudiado en otras ocasiones y en otras modalidades del español (Buzek 2010, 2012, 
2013b, 2013c, 2014a, 2014b y 2015). Por tanto, nos limitaremos tan solo a recogerlas aquí y aportar documentación textual para ellas, si la hay.

- Chingo, ga. Cub. adj.-fam. - desusada. - Equivale a chico, ca, pequeño.

- Chinguito, ta. Cub. adj. - desusada. - Diminutivo de chingo, ga.

- Jindama. Común, f. -vulg. - Manifestación de miedo o cobardía.

- Jindama. Cub. f. - vulg. - Equivale a borrachera de alcohol.

- Jiña. $C u b$. f. - muy vulg.-El excremento humano.

- Jiñar. Cub. v. n. - muy vulg. -Lo mismo que 'defecar'.

- Lea. Común. f. -Entre el vulgo de España y gran parte de América suele oirse así en vez de 'ramera' ${ }^{16}$.

- Pinreles. Cub. m. pl. -muy vulg. -Los pies, entre gente de baja estofa. En el caló gitano dícese pinré al pie.

- Pirarse. Común. v. ref. -fam. -Lo mismo que 'marcharse', 'fugarse': 'Se piró de la cárcel' ${ }^{\text {'7 }}$.

\section{REFERENCIAS BIBLIOGRÁFICAS}

Ahumada, Ignacio (dir./ed.). 2006. Diccionario bibliográfico de la metalexicografía del español (orígenes - año 2000). Jaén: Publicaciones de la Universidad de Jaén.

(dir./ed.). 2009. Diccionario bibliográfico de la metalexicografía del español (años 2001 - 2005). Jaén: Publicaciones de la Universidad de Jaén.

(dir./ed.). 2015. Diccionario bibliográfico de la metalexicografía del español 3 (2006-2010). Jaén: Publicaciones de la Universidad de Jaén.

Asociación de Academias de la Lengua Española. 2010. Diccionario de americanismos. Madrid: Santillana.

Barnet, Miguel. 2001. "Los vendedores ambulantes". Catauro 4: 135-142.

BuzeK, Ivo. 2009. Léxico gitano documentado en las variedades latinoamericanas del español. Études romanes de Brno 30 (2): 187-202. univerzita.

2010. La imagen del gitano en la lexicografía española. Brno: Masarykova

2011. Historia crítica de la lexicografía gitano-española. Brno: Masarykova univerzita.

\footnotetext{
16 “-Agradécelo a Ben Frankyn Delano. Una lea en cada foco. Tienes bifocales para el sexo contrario. Contraria contrariis curantur" (CORDE: Cabrera Infante 1967).

17 “-iMe las piraba, amigo Muela, me las piraba!” (CORDE: Insúa 1998).
} 
2012. Presencia del léxico de origen gitano en las variedades latinoamericanas del español: el caso del español de México y su caló. Études romanes de Brno 33 (2): 201-220.

2013a. Caló: una marca polifacética en la historia de la lexicografía académica. Études romanes de Brno 34 (2): 69-90.

2013b. Los diccionarios de Carlos Gagini como fuentes de estudio de gitanismos en el español de Costa Rica a finales del siglo XIX y a comienzos del siglo XX. En Miroslav Valeš y Slavomír Míča (eds.). Diversidad lingüistica del español, pp. 45-67. Liberec: Technická univerzita v Liberci.

2013c. Sobre el caló a comienzos del siglo XXI: el componente gitano en el español mexicano a través de la lexicografía. En Neus Vila Rubio (ed.). De parces y troncos. Nuevos enfoques sobre los argots hispánicos, pp. 35-76. Lleida: Edicions de la Universitat de Lleida.

2014a. El tratamiento del léxico de origen gitano en el Diccionario de Americanismos de la Asociación de Academias de la Lengua Española. Káñina XXXVIII (Especial): 19-33.

2014b. Diccionarios como testigos de la historia del léxico español: el caso de los gitanismos en el español cubano y su presencia en las obras lexicográficas de Esteban Pichardo y de Fernando Ortiz. Cuadernos del Instituto Historia de la Lengua 9: 83-104.

2015. Diccionario de mejicanismos de Féliz Ramos i Duarte (1895): fuente para la historia del léxico de origen gitano en el español mexicano. Revista Internacional de Lingüistica Iberoamericana 26: 125-144.

Camacho Barreiro, Aurora M. 2000. Fernando Ortiz, lexicógrafo. Montalbán 33: 269-278.

2003-2004. Huellas ideológicas en la lexicografía cubana. Revista de Lexicografía $\mathrm{X}: 21-38$.

2008. Las marcas sociolingüísticas en una muestra de la lexicografía cubana: tipología y evolución. Revista de Lexicografía XIV: 43-58.

2009. Abordaje diacrónico de los mecanismos de citación y de ejemplificación en la lexicografía diferencial cubana. Boletín de la Academia peruana de la lengua 47: 27-53. Castellanos, Jorge e Isabel Castellanos. 1994. Cultura Afrocubana. vol. 4. Miami: Universal.

Chávez Fajardo, Soledad. 2011. Análisis de prólogos en diccionarios diferenciales precientíficos. Descripciones, prescripciones y actitudes lingüísticas. En Elena Carmona Yanes y Santiago Del Rey Quesada (eds.). Id Est, Loquendi Peritia: Aportaciones a la Linguística Diacrónica de los Jóvenes Investigadores de Historiografía e Historia de la Lengua Española, pp. 71-77. Sevilla: Departamento de Lengua Española, Lingüística y Teoría de la Literatura, Facultad de Filología, Universidad de Sevilla.

2012. La lexicografía diferencial en Chile durante el siglo XIX: vigencia y mortandad léxica. En Emilio Montero Cartelle y Carmen Manzano Rovira. Actas del VIII Congreso Internacional de Historia de la Lengua Española. Santiago de Compostela, 14-18 de septiembre de 2009, pp. 1281-1290. Vol. 2. Santiago de Compostela: Meubook.

Coll, Magdalena. 2012. Entre la fiscalización y el registro del español del Uruguay de finales del siglo XIX: el vocabulario de Daniel Granada y el glosario de Eduardo Acevedo Díaz. En José Luis Ramírez Luengo (ed.). Por sendas ignoradas. Estudios sobre el español del siglo XIX, pp. 11-31. Lugo: Axac.

2013. Prácticas lexicográficas del siglo XIX en territorio uruguayo: de la nominación al registro de piezas de museo. Revista Argentina de Historiografía Lingüística 5 (2): 115-136.

Corominas, Joan y José Antonio Pascual. 1980-1991. Diccionario crítico etimológico castellano e hispánico. 6 vol. Madrid: Gredos. 
CuERVo, RuFino José. 1907. Apuntaciones críticas sobre el lenguaje bogotano con frecuente referencia al de los países de Hispano-América. Paris: A. \& R. Roger y F. Chernovitz, editores.

Fay, Stephen. 2010. Mapping the Cuban condition in Fernando Ortiz's Un catauro de cubanismos. New West Indian Guide 84 (1-2): 41-62.

Fernández, José Hugo. s/a. La burbuja [en línea. Disponible en http://cubamatinal.com/ Noticia.cfm?NoticiaID=8379 [Consulta 06/12/2015].

Gagini, Carlos. 1893. Diccionario de barbarismos y provincialismos de Costa Rica. San José: Tipografía Nacional.

1918. Diccionario de costarriqueñismos. San José: Imprenta Nacional,.

Hernández, Rafael. 1957. Capullito de aleli [en línea]. Disponible en http://www.guije.com/ public/cancioneros/mo_01/capullito.htm [Consulta 06/12/2015].

Huisa Téllez, José Carlos. 2011. Estudio preliminar de Diccionario de Peruanismos. Ensayo filológico de Juan de Arona. Tesis doctoral, Universidad de Augsburgo.

2013. La impronta política en la primera lexicografía hispanoamericana: republicanismo y antirrepublicanismo. Lexis 37 (2): 269-303.

2014. Representaciones sociales a través del lenguaje en la lexicografía hispanoamericana decimonónica. Boletín de Filología 49 (2): 139-159.

KrinKovÁ, ZuZana. 2013. Vzájemné ovlivňování romštiny, španělštiny a dalšich jazyků Pyrenejského poloostrova. Tesis doctoral, Universidad Carolina.

2015. From Ibearian Romani to Iberian Para-Romani varieties. Praga: Karolinum.

LaRA, Luis Fernando. 1990. Dimensiones de la lexicografía. A propósito del Diccionario del Español de México. México: Centro de Estudios Lingüísticos y Literarios.

1992. El caló revisitado. En Elisabeth Luna Traill (ed.). Scripta Philologica. In Honorem Juan M. Lope Blanch, pp. 567-592. Vol. 2. México: Universidad Nacional Autónoma de México.

1996. El Diccionario del español de México como vocabulario dialectal. En Ignacio Ahumada (ed.). Vocabularios dialectales. Revisión crítica y perspectivas. II Seminario de lexicografía Hispánica. Jaén, 28 y 29 de noviembre de 1995, pp. 15-29. Jaén: Publicaciones de la Universidad de Jaén.

1997. Teoría del diccionario monolingüe. México: El Colegio de México, Centro de Estudios Lingüísticos y Literarios.

2004. Culturas nacionales y léxico contemporáneo del español. En Jens Lüdtke y Christian Schmitt (eds.). Historia del léxico español. Enfoques y aplicaciones. Homenaje a Bodo Müller, pp. 303-315. Madrid/Frankfurt am Main: Iberoamericana/Vervuert.

(dir.). 2010. Diccionario del español de México. México: El Colegio de México, Centro de Estudios Lingüísticos y Literarios.

2011. El símbolo, el poder y la lengua. En Silvia Senz y Montserrat Alberde (eds.). El dardo en la Academia, pp. 315-341. Vol. 1. Barcelona: Melusina.

LAURIA, DANIELA. 2011. Apuntes para una historia de la producción lexicográfica monolingüe en la Argentina: etapas del proceso de diccionarización y modalidades diccionarísticas entre 1870 y 1910. Boletín de Filología 46 (1): 105-151.

2013a. Introducción: Tradición e innovación en la historia de la producción lexicográfica del español. El diccionario como objeto de investigación: aportes desde distintas perspectivas teórico-metodológicas. Revista Argentina de Historiografía Lingüistica 5 (1): 1-5.

2013b. Introducción: Tradición e innovación en la historia de la producción lexicográfica del español y del portugués en América del Sur. El diccionario como objeto 
de investigación: aportes desde distintas perspectivas teórico-metodológicas. Revista Argentina de Historiografía Lingüistica 5 (2): 89-93.

Oramas, Faustino. 1968. Pacho Alonso y El Guayabero [en línea]. Disponible en http://www. lajiribilla.co.cu/2006/n295_12/en_foco/nota.htm [Consulta 06/12/2015].

Ortiz, Fernando. 1923. Un catauro de cubanismos. Apuntes lexicográficos. La Habana: Revista Bimestre Cubana.

1985. Nuevo catauro de cubanismos. La Habana: Editorial de Ciencias Sociales.

Pabanó, F. M. [Manzano López, Félix] 2007 [1915]. Historia y costumbres de los gitanos. Colección de cuentos viejos y nuevos, dichos y timos graciosos, maldiciones y refranes netamente gitanos. Diccionario español-gitano-germanesco. Dialecto de los gitanos. Mairena de Aljarafe: Extramuros.

Pichardo, Esteban. 1836. Diccionario provincial de voces cubanas. Matanzas: Imprenta de la Real Marina.

Prieto García-Seco, David. 2014. Cuatro siglos de lexicografía española. La recepción de Tirso de Molina en los diccionarios del español. A Coruña: Universidade da Coruña, Servizo de Publicacións. Anexos de Revista de Lexicografia, 24.

Ramos i Duarte, Féliz. 1895. Diccionario de mejicanismos. Colección de locuciones i frases viciosas, con sus correspondientes críticas i correcciones fundadas en autoridades de la lengua; máximas, refranes, provincialismos y retoques populares de todos los Estados de la República Mejicana. Méjico: Imprenta de Eduardo Dublan.

Real Academia Española. s/a. Corpus Diacrónico del Español (CORDE) [en línea]. Disponible en http://corpus.rae.es/cordenet.html [Consulta 06/03/2015].

s/a. Corpus de Referencia del Español Actual (CREA) [en línea]. Disponible en http://corpus.rae.es/creanet.html [Consulta 06/03/2015].

s/a. Fichero General [en línea]. Disponible en http://web.frl.es/fichero.html [Consulta 30/11/2015].

s/a. Nuevo Tesoro lexicográfico de la Lengua Española [en línea]. Disponible en http://ntlle.rae.es/ntlle/SrvltGUILoginNtlle [Consulta 30/11/2015].

Rebolledo, Tineo. 2006 [1909]. Diccionario gitano-español y español-gitano. Cádiz: Universidad de Cádiz.

Rivero, MónICA. 2013. ¿Se perdió hasta el paripé? Cuba debate [en línea]. Disponible en http:// www.cubadebate.cu/opinion/2013/08/06/se-perdio-hasta-el-paripe/\#.VR6SEOH3ExI [Consulta 06/12/2015].

Ruhstaller, Stefan y María Dolores Gordón (eds.). 2010. Diccionario y aprendizaje del español. Bern: Peter Lang.

Senz, Silvia. 2011. Una, grande y (esencialmente) uniforme. La RAE en la conformación y expansión de la "lengua común". En Silvia Senz y Montserrat Alberde (eds.). El dardo en la Academia, pp. 9-302. Vol. 2. Barcelona: Melusina.

SuÁrez, Constantino. 1921. Vocabulario cubano. Suplemento a la $14^{a}$ edición del Diccionario de la R. A. de la Lengua. La Habana/Madrid: Librería Cervantes de Ricardo Veloso/ Librería de Perlado, Páez y Cía.

Valdés Alonso, Francisco. 2014. El Indio “Angá” pone sandunga con el Ireme. TelePinar [en línea]. Disponible en http://www.telepinar.icrt.cu/2014/08/26/el-indio-anga-ponesandunga-con-el-ireme/ [Consulta 06/12/2015].

West-Durán, Alan. 2009. Colores sin Benetton, pero al ritmo de reguetón. Encuentro de la cultura cubana 53-54: 68-73.

Zimmermann, Klaus. 2003. El fin de los diccionarios de americanismos. La situación de la lexicografía del español de América después de la publicación de los Diccionarios contrastivos del español de América. Revista Internacional de Lingüistica Iberoamericana 1: $71-83$. 
2012. Diccionarios, identidad e ideología lingüística. Una reseña y evaluación comparativa del Diccionario del español de México y del Diccionario de mexicanismos. Revista Internacional de Lingüística Iberoamericana 19: 167-181.

Fuentes de eJemplos del Corpus Diacrónico del EsPañol (CORDE)

Bobadilla, Emilio. 2003 [1903]. A fuego lento. Alicante: Biblioteca Virtual Miguel de Cervantes, Universidad de Alicante.

Cabrera Infante, Guillermo. 1967. Tres tristes tigres. Barcelona: Seix Barral.

Carlos Felipe [Fernández Santana, Carlos]. 1978 [1949]. El travieso Jimmy. La Habana: Letras cubanas.

InsÚA, AlBerto. 1998. El negro que tenía el alma blanca. Madrid: Castalia.

Fuentes del Corpus de Referencia del Español Actual (CREA)

Évora, Tony. 1997. Orígenes de la música cubana. Los amores de las cuerdas y el tambor. Madrid: Alianza.

OraL. s/a. Discurso de Fidel Castro en el acto central por el 45 aniversario del asalto a los cuarteles Moncada...

Ortiz, FernANDO. 1975. La música afrocubana. Gijón: Ediciones Júcar. 
